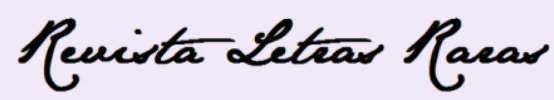

ISSN: 2317-2347 - Vol. 5, Ano 5, № 1 - 2016

\title{
Os sinais de letras nas Libras: colonização ou línguas em contato?
}

\author{
Nelson Pimenta Castro* \\ Geisielen Santana Valsechi* \\ Luiz Carlos Barros de Freitas*
}

\begin{abstract}
Resumo: Este é um estudo que propõe uma reflexão a partir das discussões bastante polarizadas em diversas comunidades surdas desta segunda década do milênio sobre a existência dos sinais produzidos em línguas de sinais (LS) com letras do alfabeto como produto da influência das línguas orais (LO) como línguas hegemônicas e colonialistas (FREITAS, 2009, 2013) e, de outro lado, como resultado do fenômeno de línguas em contato (RODRIGUES et al, 2014). Baseia-se nos dados gerados em narrativas (FABRÍCIO et al in PEREIRA, 2009) de seis surdos brasileiros jovens, acadêmicos e usuários da Libras ${ }^{1}$ e um surdo adulto francês, professor universitário e usuário da $\mathrm{LSF}^{2}$. O estudo faz uma análise micro etnográfica (GARCEZ et al, 2014) de abordagem metodológica qualitativa e interpretativa (SILVERMAN, 2011). Os resultados demonstraram a qualificação do discurso surdo da atualidade e que o uso de letras nos sinais das línguas de sinais pode representar, em alguma medida, uma contribuição para o aprofundamento da construção do conhecimento surdo. Palavras-chave: Libras. Colonialismo linguístico. Línguas em contato.
\end{abstract}

\section{SIGNS OF LETTERS IN LIBRAS: COLONIALISM OR LANGUAGES IN CONTACT?}

\begin{abstract}
This paper proposes a reflection from quite polarized discussions into many deaf communities of this second decade of the millennium about the existence of signals produced in Sign Languages with letters from the alphabet as a product of the influence of the oral languages as hegemonic and colonialist languages (FREITAS, 2012) or as a result of languages in contact social phenomenon (RODRIGUES et al, 2014). The study is based on data generated in narratives (FABRICIO et al in PEREIRA, 2009) of seven young Brazilian academic deaf users of Brazilian Sign Language and one deaf French adult teacher, with a microetnografic analysis (GARCEZ et al, 2014) and qualitative and interpretative methodological approach (SILVERMAN, 2011). The results has demonstrated the better qualification of the speech of the deaf today and also that the use of letters in some signs of Sign Languages can represent, to some extent, a contribution to the deepening of the construction of knowledge by the deaf people.
\end{abstract}

Keywords: Brazilian Sign Language. Linguistic colonialismo. Languages in touch.

\section{Introdução}

\footnotetext{
* Prof. Me. Nelson Pimenta de Castro, doutorando em Estudos de Tradução pela UFSC, professor do INES Instituto Nacional de Educação de Surdos; email: npcastro6@gmail.com.

* Profa. Me. Geisielen Santana Valsechi, mestra em Estudos de Tradução pela UFSC, professora do Colégio de Aplicação da UFSC; email: geisielenvalsechi@gmail.com.

* Prof. Me. Luiz Carlos Barros de Freitas, doutorando em Estudos da Linguagem pela PUC-Rio/UFRJ, professor da Faculdade de Letras da UFRJ; email: luiz991746620@letras.ufrj.br.

${ }^{1}$ LIBRAS - Língua Brasileira de Sinais ou Língua de Sinais Brasileira. Brazilian Sign Language.

${ }^{2}$ LSF - Língua de Sinais Francesa, ou Langue de Signes Française
} 


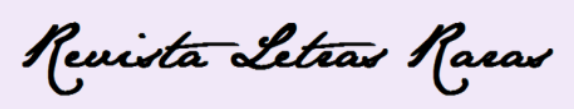

ISSN: 2317-2347 - Vol. 5, Ano 5, № 1 - 2016

Este trabalho é feito a partir da pergunta: "Como o sujeito surdo percebe, atualmente, a utilização de letras do alfabeto em sinais das línguas de sinais?" e considera o pressuposto de que os surdos usuários de línguas de sinais são sujeitos bilíngues e bi culturais (THOMA et $a l, 2005 ;$ 2006), que vivem uma experiência visual de vida (SKLIAR, [1998] 2005), e são integrantes de minorias linguísticas brasileira e francesa em contextos de hegemonia de poder da língua portuguesa (FREITAS, 2009; 2013) e francesa. Serão doravante denominados surdos.

A pesquisa baseia-se nos dados gerados em narrativas (FABRÍCIO et al in PEREIRA, 2009) de seis surdos brasileiros jovens, acadêmicos e usuários da Libras e um surdo adulto francês, professor universitário e usuário da LSF. Todos os participantes forneceram seus respectivos documentos de "Termo de Consentimento Livre e Esclarecido" sobre a sua contribuição.

O estudo faz uma análise micro etnográfica (GARCEZ et al, 2014) de abordagem metodológica qualitativa e interpretativa (SILVERMAN, 2011), ou seja, buscando a investigação das especificidades das escolhas pessoais no processo de condução da ação social local e temporalmente situada.

É um estudo que propõe uma reflexão a partir das discussões bastante polarizadas que se dão atualmente em diversas comunidades surdas brasileiras e francesas desta segunda década do milênio sobre a existência dos sinais produzidos em línguas de sinais contendo letras do alfabeto, de um lado sendo argumentado que se trata de um produto da influência das línguas portuguesa e francesa como línguas hegemônicas e de ideologia colonialista (FREITAS, 2009, 2013) e, do outro lado, que se trata do resultado do fenômeno de línguas em contato (RODRIGUES et al, 2014) no Brasil e na França multilíngues, onde nos contextos da vida surda o português e a Libras, no Brasil, e o francês e a LSF, na França, estão continuamente em uso.

Surdos brasileiros são, como os surdos franceses, minorias linguísticas. Segundo a OMS $^{3}$ (EXAME, 2016), pessoas surdas ou deficientes auditivas constituem $5 \%$ da população mundial e esta condição de minoria começa em família, pois LANE (1996, p.30) afirma que "apenas cinco a dez por cento dos surdos têm pais surdos". A origem das discussões sobre línguas de sinais versus línguas orais se perde no tempo, mas sempre esteve na pauta de conversas e narrativas surdas, pois o assunto línguas sempre foi muito importante para estas

\footnotetext{
${ }^{3}$ OMS - Organização Mundial da Saúde
} 


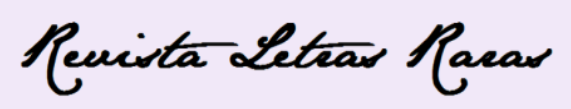

ISSN: 2317-2347 - Vol. 5, Ano 5, № 1 - 2016

minorias linguísticas, até porque segundo BAKHTIN (1997, p.280), "todas as esferas da atividade humana, por mais variadas que sejam, estão sempre relacionadas com a utilização da língua”.

\section{O sujeito surdo, suas identidades e sua cultura}

Uma das marcas atribuídas na composição da multifacetagem identitária (HALL, 2006) líquida (BAUMAN, 2005) dos surdos é que a sua forma de ouvir é realizada em grande parte através dos olhos; portanto, a sua percepção visual ganha mais esta função.

Strobel esclarece a sua perspectiva sobre as identidades surdas quando afirma:

Povo surdo poderia ser os surdos das zonas rurais, os surdos das zonas urbanas, os surdos índios, as mulheres surdas, os surdos sinalizados, os surdos oralizados, os surdos com implante coclear, os surdos gays e outros. Estes surdos também se identificam com o povo surdo apesar de não pertencerem às mesmas comunidades surdas. (STROBEL, 2008, p.32).

A autora esclarece o seu conceito de comunidades surdas e afirma:

Então entendemos que a comunidade surda de fato não é só de sujeitos surdos, há também sujeitos ouvintes ${ }^{4}$-membros de família, intérpretes, professores, amigos e outros- que participam e compartilham os mesmos interesses em comum em uma determinada localização. (STROBEL, 2008, p.32).

A partir daí, é notada uma imbricação entre "Ser Surdo" e "contexto surdo", o que se aproxima do que este trabalho considera em relação às identidades, ou seja, como construtos sociais fragmentados, múltiplos (MOITA LOPES, 2003; BAUMAN, 2005; FABRÍCIO et al, 2009; DE FINA, 2011), em processo e altamente dependentes de aspectos contextuais discursivos, micro e macro interacionais, socioculturais e históricos, local onde se subjetivam os sujeitos surdos e a sua cultura surda.

Sobre cultura surda, o referencial assumido nesta pesquisa é o de STROBEL (2008). A pedagoga e doutora surda define:

Cultura surda é o jeito de o sujeito surdo entender o mundo e de modificá-lo a fim de torná-lo acessível e habitável ajustando-o com as suas percepções

\footnotetext{
${ }^{4}$ Ouvintes - pessoas não surdas. Nota dos autores
} 


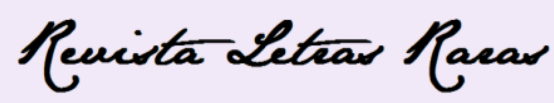

ISSN: 2317-2347 - Vol. 5, Ano 5, № 1 - 2016

visuais, que contribuem para a definição das identidades surdas e das "almas" das comunidades surdas. Isto significa que abrange a língua, as ideias, as crenças, os costumes e os hábitos do povo surdo. (STROBEL, 2008, p. 24).

Pelas definições acima, as identidades surdas e a cultura surda são definidas tendo como base o jeito surdo de entender o mundo e subjetiva-lo e a si próprio, portanto passam a ser interpretadas, neste trabalho, como instâncias localizadas em patamares além de questões de gênero, orientação sexual, religião, etnia ou nacionalidade dos surdos, ou seja, o sujeito surdo encontra na sua percepção visual da vida a forma de constituir o que STROBEL (2008, p. 24) classifica como povo surdo.

Em relação à língua humana, Bakhtin afirma:

De fato, o ouvinte que recebe e compreende a significação (linguística) de um discurso adota simultaneamente, para com este discurso, uma atitude responsiva ativa: ele concorda ou discorda (total ou parcialmente), completa, adapta, apronta-se para executar etc., e esta atitude do ouvinte está em elaboração constante durante todo o processo de audição e de compreensão desde o início do discurso, às vezes já nas primeiras palavras emitidas pelo locutor. (BAKHTIN, 1997, p. 291)

As referências ao "processo de audição" e à "atitude do ouvinte" de Bakhtin são aqui interpretadas estendendo-se em todas as possibilidades para os surdos, pois o autor não levou em consideração a existência das línguas de sinais, já que na época em que escreveu o texto acima citado, ou seja, na primeira década do séc. XX, as línguas de sinais ainda não tinham sido caracterizadas em seu estatuto linguístico como línguas e não apenas linguagens.

Os estudos do linguista Stockoe na década de 1960 possibilitaram uma importante quebra de paradigmas. Stockoe postulou (FERNANDES, 2011, p. 57) que a língua de sinais americana não era apenas uma pantomima ou uma linguagem gestual simples e não sistematizada como se acreditava até então, mas sim uma língua com todas as características morfológicas, fonológicas, fonéticas, sintáticas, pragmáticas e semânticas que pudessem garantir este seu estatuto linguístico. Portanto, a partir dos estudos de Stockoe sobre a ASL, as demais línguas de sinais de todo o mundo ganharam o seu estatuto linguístico e passaram a ser estudadas, pesquisadas e consideradas como línguas.

A linguagem não se refere somente à fala, mas reflete a nossa cultura, é um processo de comunicação que possibilita a compreensão entre os seres humanos, sendo um aspecto fundamental no processo de desenvolvimento da humanidade. Entre os diferentes tipos de linguagem do surdo, VYGOTSKY (1989) destaca a mímica (como se refere à língua de 


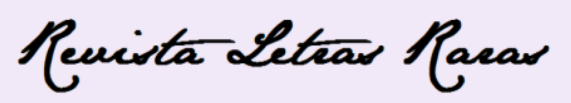

ISSN: 2317-2347 - Vol. 5, Ano 5, № 1 - 2016

sinais) e afirma o seguinte:

A luta entre a linguagem oral e a gestual, apesar de todas as boas intenções dos pedagogos, acaba com a vitória da mímica, isso não é porque a mímica constitua, desde o ponto de vista psicológico, a verdadeira língua do surdomudo, nem porque seja fácil como dizem muitos professores, mas porque ela é verdadeira língua em toda a riqueza de seu significado funcional, enquanto a pronúncia oral das palavras inculcadas artificialmente representa só um modelo da linguagem viva. (VYGOTSKY apud SKLIAR, 1997, p. 122 123)

Os surdos usuários de línguas de sinais utilizam as suas mãos e as expressões faciais e corporais para falar a sua língua de sinais, que é de modalidade visual-espacial (PIMENTA et al, 2013, p. 25), diferente do português e do francês, por exemplo, que são línguas oralauditivas. Sendo assim, nesta pesquisa admite-se que a Libras e o português no Brasil, e a LSF e o francês na França, são línguas que partilham a complexidade dos respectivos espaços sociais, políticos, culturais e identitários dos dois países, embora apresentem aspectos gramaticais (morfológicos, fonológicos, fonéticos, sintáticos, pragmáticos e semânticos) bastante diferentes.

É notório que o conhecimento humano está registrado, em grande parte, na escrita das línguas orais, pois apesar de existirem algumas pesquisas para a escrita das línguas de sinais, até a presente data nenhuma destas se tornou suficientemente conhecida nem legalizada, de tal forma que os registros em vídeo digital vêm ganhando cada vez mais notoriedade, especialmente nas últimas duas décadas, com a popularização e desenvolvimento das tecnologias digitais.

A partir dessa realidade, é de se compreender que os surdos que se utilizam apenas das suas línguas de sinais encontrem mais dificuldades para se integrar nas sociedades, que são majoritariamente ouvintes e que, em grande número, nem cogitam ser bilíngues, pois não têm informação sobre a importância das LS para os surdos. Muitos ouvintes e até mesmo alguns surdos nem mesmo sabem que os gestos e expressões faciais dos surdos fazem parte da constituição de uma língua, e nem que esta movimentação não é a produção manual da língua oral, pois tanto no Brasil quanto na França, as discussões sobre a importância das línguas de sinais para a constituição identitária e cultural dos surdos está bastante avançada, mas apenas nos contextos educacionais e acadêmicos.

Por tudo isto, neste trabalho é assumido que o bilinguismo dos surdos deve se constituir de língua de sinais como primeira língua (L1) e língua oral escrita como segunda língua (L2), conforme proposto por FERNANDES (2011, p. 105), para que surdos e ouvintes 


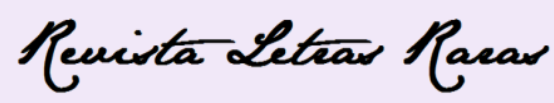

ISSN: 2317-2347 - Vol. 5, Ano 5, № 1 - 2016

possam compartilhar o conhecimento nos ambientes educacionais, corporativos e na sociedade em geral.

\section{Línguas de sinais e orais em contato no Brasil e na França}

No Brasil e na França, as suas respectivas línguas de sinais sempre estiveram no cerne de discussões com foco nas disputas de poder entre ouvintes e surdos, dada a hegemonia das línguas orais desses países, que são línguas de prestígio secularmente construído no imaginário das sociedades brasileira e francesa, respectivamente, enquanto as línguas de sinais sequer eram consideradas línguas até há pouco tempo, como visto anteriormente.

O Brasil é uma nação multilíngue, mas o Estado Brasileiro sempre resistiu em aceitar esta ideia e a língua portuguesa vem se consolidando no patamar de única língua oficial e de maior prestígio desde o século XVIII. Na França ocorre o mesmo, e o francês é a língua nacional. Apenas recentemente os governos vêm cedendo às pressões dos movimentos sociais, adotando medidas que possibilitem que as demais línguas em uso pela população brasileira e francesa sejam devidamente respeitadas, ainda que o português e o francês mantenham a sua hegemonia. No caso da língua de sinais brasileira, esse processo foi muito incrementado com a sua legalização pela Lei 10.436/2002 (BRASIL, 2002) e o seu atual processo de regulamentação pelo Decreto 5.626/2005 (BRASIL, 2005).

Em países linguísticamente diversos como o Brasil e a França, o fenômeno de línguas em contato é mais do que aceitável: é plenamente esperado, e ocorre provocando inúmeras consequências. Uma delas é o fenômeno de empréstimo linguístico que provoca a utilização de letras do alfabeto na constituição de sinais da Libras e da LSF, e que atualmente vem suscitanto discussões às vezes acirradas em redes sociais digitais e espaços de discussão acadêmica, escolar e social em geral nos dois países.

Há diversas definições e especificidades técnicas para os empréstimos linguísticos, que não cabem neste estudo, que apenas admite e encara o fenômeno de importação, cópia, troca e/ou transferência linguística como um dos elementos de causa e efeito da dinamicidade das línguas. Segundo Nascimento:

O termo empréstimo, borrowing em inglês, tem sido discutido por diversos linguistas que julgam esta denominação como inadequada. Por isso, há literaturas que oferecem outros termos alternativos para denominar este mesmo fenômeno. Cópia lexical é uma dessas terminologias opcionais 


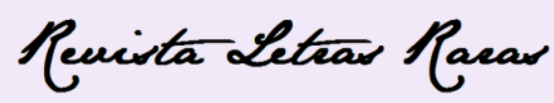

ISSN: 2317-2347 - Vol. 5, Ano 5, № 1 - 2016

sugerida pelo linguista William Thurston (1987), como mencionado por Crowley (1997, p. 240). Newmark (1981, apud Aubert, 2003, p. 29) usa o termo transferência; já importação é a terminologia usada por Correia e Lemos (2005, p.52), entre outros. (NASCIMENTO, 2011, e-p. 230)

As letras do alfabeto não são de propriedade dos ouvintes, são signos que podem ser compartilhados entre ouvintes e surdos para a transmissão do conhecimento em ambientes bilíngues em que surdos e ouvintes interagem muitas vezes fazendo-se valer da datilologia, que é a técnica de configurar a mão representando as letras do alfabeto para formar palavras. Sua origem se perde no tempo e certamente está atrelada à interação entre os ouvintes e os surdos. Segundo Nascimento:

A datilologia é muito útil às línguas de sinais. Provavelmente, é decorrente do contato de educadores ouvintes com aprendizes surdos. Faz-se necessário, neste momento, distinguir a datilologia pura de empréstimos lexicais a partir da datilologia, apesar de que em alguns momentos elas serão usadas como sinônimas. A datilologia em si não é um empréstimo lexical, apenas pode preencher uma lacuna em determinado momento e não se tornar parte do sistema. Já o empréstimo lexical por meio da datilologia, como dito por Baker-Shenk e Cokely, tornam-se mais semelhantes ao sistema com aparência cada vez mais nativa, ou seja, são integrados ao sistema. Machabée (1995, p.31), de acordo com Battison (1978), diz que a datilologia só se torna empréstimo lexical quando é reestruturada, ou seja, depois que adquire uma aparência mais adaptada à língua de sinais. Portanto, Battison considera as datilologias reestruturadas como empréstimos lexicais. (NASCIMENTO, 2011, p. 387)

Bons exemplos dessa reestruturação acima mencionada, na língua de sinais brasileira, e que são utilizados em grande parte do território nacional, são os sinais NUNCA, ALUNO, PAI, MÃE, AZUL, ACHO e outros, que se lexicalizaram e se tornaram sinais a partir das letras do alfabeto e que são, eventualmente, também denominados sinais soletrados.

A datilologia tem sido bastante utilizada na educação dos surdos. A formação das culturas nacionais contribuiu para criar padrões de alfabetização universais, generalizou uma única língua vernacular como o meio dominante de comunicação em cada nação como um todo, buscou a criação de uma cultura homogênea e manteve instituições culturais nacionais.

Grande parte dos surdos brasileiros se considera integrante da cultura surda (STROBEL, 2008), minoritária e inserida em uma cultura de maior abrangência, a brasileira que, por conta da globalização, traz em si o paradoxo da tendência a uma similarização de valores, ideais e padrões comportamentais nas culturas e, em contrapartida, a tendência ao fortalecimento identitário, ao que Freitas faz referência: 


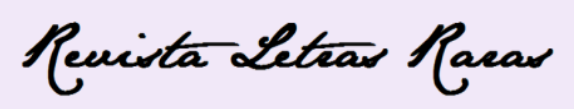

ISSN: 2317-2347 - Vol. 5, Ano 5, № 1 - 2016

Há uma lacuna interessante na contradição entre a tendência à equalização das culturas e a fragmentação de valores culturais, que é a oportunidade de fortalecimento de algumas identidades até então frágeis, como a dos surdos, que traz em si os valores da cultura surda. (FREITAS, 2009, p.33)

No Brasil deste início de século há a contradição da implantação oficial do bilinguismo na educação dos surdos pelo PNE e, em contrapartida, a prática simultânea do oralismo e do bilinguismo nas escolas brasileiras. A situação na França é bastante parecida, com práticas educacionais oralistas e bilíngues convivendo no contexto educacional.

Por outro lado, o fortalecimento das identidades surdas, a melhoria da educação dos surdos após a legalização da Libras e da LSF e o aumento do acesso à informação com a popularização de novas tecnologias de comunicação criaram um cenário diferente do que havia no séc. XX, e um exemplo disto é a forte polarização em discussões entre os surdos sobre o uso ou não de sinais que contenham as configurações de mãos (PIMENTA et al, 2013) que representam as letras do alfabeto, e que gerou a perguta desta pesquisa: "Como o sujeito surdo percebe, atualmente, a utilização de letras do alfabeto em sinais das línguas de sinais?”.

Grande parte dos surdos deste início do século XXI qualificou o seu discurso, vem se conscientizando de direitos e deveres cidadãos, enfim, em grande medida abandonou a narrativa repetitiva de que a comunidade surda sofreu e foi influenciada pelo oralismo etc. Nos estudos atuais sobre surdez, busca-se principalmente entender a vida surda e criar novos métodos e modelos que visem à facilitação da sua inclusão social (CASTRO, 2012; THOMA et al, 2005, 2006; FREITAS, 2009; 2013)

\section{Análise de narrativas surdas e o uso de sinais com letras do alfabeto}

Este trabalho se baseia na concepção de narrativa de Fabrício et al, que apresenta contornos bem definidos e bastante complexos:

A narrativa, portanto, constitui uma prática discursivo-identitária que não pode ser estudada desligada de aspectos contextuais e locais, nem em separado das relações sociais, pois sua coerência não se encontra só no texto, mas depende do background e das expectativas de todos os participantes (narrador e interlocutores), que, em conjunto, negociam e interpretam mutuamente os significados propostos. (FABRÍCIO et al, 2009, p. 45)

Portanto, o posicionamento assumido pela pesquisa é de que a narrativa é tratada 


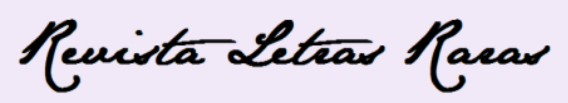

ISSN: 2317-2347 - Vol. 5, Ano 5, № 1 - 2016

como uma performance social (BAUMAN, 1986, p. 3) que nos ajuda a atribuir significado à vida e às coisas do mundo, além de nos fazer compreender a nós mesmos através da nossa subjetivação como sujeitos constituídos e constituintes do contexto sócio histórico que é (re)construído na narrativa (SILVA, 2014, p. 4).

O corpus da pesquisa foi constituído dos dados gerados em narrativas (FABRÍCIO et al in PEREIRA, 2009) de seis surdos brasileiros jovens moradores da região sudeste do país, acadêmicos e usuários da Libras, e um surdo adulto francês, professor universitário em Paris e usuário da língua de sinais francesa. As interações com os jovens brasileiros foram presenciais e, com o adulto francês, na modalidade a distância, através de softwares de comunicação visual por computador. O estudo faz uma análise microetnográfica (GARCEZ et $a l, 2014)$ de abordagem metodológica qualitativa e interpretativa (SILVERMAN, 2011) e as transcrições seguiram o modelo adotado por Quadros et al (2004).

As narrativas foram produzidas a partir de entrevistas com as seguintes perguntas em línguas de sinais (brasileira ou francesa, conforme o interlocutor):

1) DATILOLOGIA BOM OU RUIM? PORQUE? (Tradução livre: A datilologia é boa ou ruim? Por que?)

2) QUEM USAR DATILOLOGIA? SURDO IDOSO, PROFESSORES OUVINTES, SURDOS JOVENS ORALIZADOS, SURDOS JOVENS LS ETC. EXEMPLOS CADA UM. (Tradução livre: Quem usa a datilologia? Dê exemplos de como os surdos, os idosos, os professores ouvintes, os surdos jovens oralizados, os surdos jovens usuários de língua de sinais e outros que usam a datilologia.)

Os resultados demonstraram que, no contexto analisado, os surdos demonstraram que estão conscientes e articulados com as suas questões identitárias e culturais sem repetir o padrão discursivo notório de sofrimento e opressão que vigiu durante décadas a fio. Hoje a discussão se qualificou e as narrativas analisadas demonstraram posicionamentos claros e concatenados, que consideram as dificuldades pelas quais passam as minorias linguísticas sob o viés dos estudos culturais e com pensamento articulado, acatando que o início do uso das letras nos sinais se perde no tempo e enxergando que, na interação proporcionada pelas línguas em contato, há oportunidades de construção de conhecimento.

Apesar desta pesquisa adotar uma abordagem qualitativa, um resultado quantitativo nos pareceu importante: na totalidade das produções de narrativas analisadas foram encontrados apenas vinte e seis por cento de palavras (sinais) iniciados com configurações de 


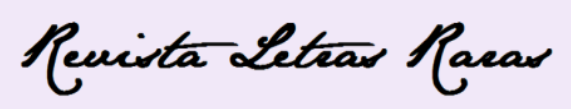

ISSN: 2317-2347 - Vol. 5, Ano 5, № 1 - 2016

mãos referentes às letras do alfabeto. Se for considerada a situação de prestígio linguístico do português e do francês em contraposição à desvalorização da Libras e da LSF respectivamente, e o longo tempo de massacre cultural e linguístico a que os surdos foram submetidos com a imposição do oralismo especialmente durante quase todo o século XX, pode-se concluir que este é um número bastante tímido, ou seja, conclui-se que mesmo a despeito da proibição das línguas de sinais durante tantos anos, os surdos brasileiros e o francês entrevistados demonstraram que pelo menos nessas comunidades surdas as suas respetivas línguas de sinais conseguiram se manter fortes e atuantes.

Os trechos mais relevantes das respostas foram os seguintes:

a) No excerto das linhas 05 a 26 o aluno surdo demonstra que quando ele era criança e teve interesse em saber o significado da palavra cultura, o seu pai explicou fazendo uma correlação entre aspectos típicos de cultura como teatro, cinema e diferenças locais e a letra $\mathrm{C}$, e este signo, mais tarde, possibilitou que ele atribuísse significado ao respectivo sinal da Libras, que é feito com a letra $\mathrm{C}$ em movimento pelo braço oposto, ou seja, a letra $\mathrm{C}$ serviu de suporte visual para que ele fizesse as devidas conexões dos diversos conceitos que estão envolvidos na palavra (sinal) cultura.

006 UMA PALAVRA IMPORTANTE PARA USAR PORTUGUÊS C-U-L-T-U-R-A.

007 EU ANOS PASSADOS, EU PEQUENO (exp.f. negativa/interrogativa) EU VER ONDE (exp.f. negativa/interrogativa)

008 QUALQUER E VER A PALAVRA C-U-L-T-U-R-A EU SABER-NÃO (exp.f. negativo/interrogativo)

009 EU NADA CONHECER E ENTÃO EU PERGUNTAR MEU P-A-I. Nome do pai C-U-L-TU-R-A O QUE? (exp.f. interrogativo)

010 SABER (exp.f. exclamativo) P-A-I RESPONDER NUNCA (exp.f. negativa/exclamativo)

011 DATILOLOGIA DA PALAVRA ELE-aponta O PAI PEGAR O SINAL NUNCA (exp.f. negativa/exclamativo) NUNCA! afirmativo)

012 ELE-aponta PAI ELE SEMPRE EXPLICAR. HÁ C-U-L-T-U-R-A (exp.f. exclamativo e 013 CONHECER SABER CATEGORIA TEATRO CATEGORIA CINEMA CONHECER LÁAPONTAR lugar. (exp.f. exclamativo e afirmativo)

014 mostrando movimento-ENTENDER CONHECER LÁ-apontar lugar É SINAL C-U-L-T-U-R$\mathrm{A}$, DATILOLOGIA É!

015 EU olhar-pai (exp.f. exclamativo e afirmativo) DATILOLOGIA É PRIMEIRO apontar-pai

016 ANOS PASSAR, OUTRA VEZ (exp.f. exclamativo/interrogativo) O QUÊ TER NOME

017 CONHECER C-U-L-T-U-R-A E pai-RESPONDER (exp.f. exclamativo e afirmativo) CERTO USAR DATILOLOGIA, DATILOLOGIA,

018 DEPOIS ANOS PASSAR REPETIR VÁRIOS REPERTIR DATILOLOGIA USAR 019 chamar apontar-pai CONHECER LÁ-apontar lugar $C^{5}$.

\footnotetext{
${ }^{5}$ Letra "C" é o sinal da palavra CULTURA, usando como movimento da boca (oralizando à palavra cultura demostrando o sinal “C”, configuração de mão CM29 (Anexo 1).
} 


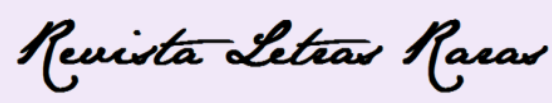

ISSN: 2317-2347 - Vol. 5, Ano 5, № 1 - 2016

020 MOSTRAR O SINAL C TEMPOS PASSAR LÍNGUA NATURAL <NUNCA〉 (exp.f. negativa/exclamativo) SINAL,

021 MAS ANOS PASSAR (exp.f. exclamativo/afirmativo) MUITOS ANOS PASSAR

022 AGORA TER VÁRIOS SINAIS CRESCER PRIMEIRO SINAL mostrando $\mathrm{C}^{6}$,

023 SEGUNDO SINAL (Configuração de mão $\mathrm{CM} 48)^{7}$,

024 TER (CM48) OUTRO SINAL,

025 TER (CM48 outro sinal) E (Configuração ${ }^{8}$ e exp.f. exclamativa) TER VÁRIOS,

026 MAS NATURAL NÃO TER OBRIGAR (exp.f. exclamativo de sério)

027 MINHA FAMÍLIA ACONTECER DENTRO PALAVRA C-U-L-T-U-R-A NÃO (exp.f. exclamativo e afirmativo)

b) No excerto das linhas 75 a 78, a aluna surda afirma que o uso da letra do alfabeto em sinais a ajuda na compreensão dos conceitos dos próprios sinais, pois atribui importância à língua portuguesa como fator de contribuição para o aprofundamento do conhecimento e atribuição de significado ao sinal. Parece ser um posicionamento de oportunizar a condição de prestígio do português para interagir com esta língua e enriquecer a Libras. exclamativo-bom!)

075 ENTÃO FOCO LETRA DO POSITIVO É O QUE EXPLICAR PARECE BEM (exp.f. 076 AJUDAR-ME PORQUE LETRAS DAR-ME MAIS CONHECIMENTOS

077 PORQUE USA INFORMAÇÃO DAS PALAVRAS CONHECER E

078 TAMBÉM O PORTUGUÊS É PRINCIPAL IMPORTANTE >C-L-A-R-O<

c) O excerto das linhas 100 a 105 demonstra que o professor francês surdo faz referência ao sinal oui como sendo uma lexicalização das três letras o-u-i juntas, formando um só sinal com a mão configurada na CM45 (vide Anexo 1) e em movimento repetido, atribuindo importância às letras do alfabeto na formação de palavras na LSF através de sua expressão facial afirmativa e positiva no momento da demonstração. Essa avaliação é ratificada por meio da afirmação de que o uso de letras nos sinais da LSF vem de um longo passado e que não vê problema algum nisto.

100 ENTÃO ESSA-“H” (honesto do português) E O TERCEIRO CERTO ${ }^{9}$ (exp.f. olhar aumentativo/afirmativo) AH-ESSE <O QUÊ?> O-U-I AH (exp.f. olhando para à mão/boca aberta/afirmativo) palavra O-U-I.

101 PENSAR-SIM (exp.f. exclamativo/afirmativo do sinal) PASSADO. AGORA O QUARTO sinal "F" F-R-E-R-E É IRMÃO DEPOIS IRMÃ ELE E EU

102 MESMO NASCER DOIS-IRMÃOS apontar aos dois lados IRMÃ S-O-E-U-R (afirmativa) RA-R-E NÃO TER MUITO, POUQUÍSSIMO sinal "R" (exp.f. negativo/exclamativo-muito pouco) (significa raro).

103 COR “5” configuração de mão V-E-R-T É sinal 5-V (significa verde), AGORA EMBAIXO

\footnotetext{
${ }^{6}$ Letra "C", CM29, com o braço, movendo-se de cima para baixo em movimento reto (Anexo 1)

${ }^{7}$ Mostra o sinal que existe na CM48 localizado na lateral da testa em movimento semi-circular (Anexo 1).

${ }^{8}$ CM48 é usada de duas formas diferentes (Anexo 1).

${ }^{9} \mathrm{CM} 45$ no espaço neutro, em movimento vertical repetitivo.
} 


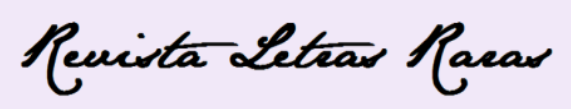

ISSN: 2317-2347 - Vol. 5, Ano 5, № 1 - 2016

"J" J-A-U-N-E É sinal "J" (apontando ao lado boca) (significa de amarelo), sinal "B" B-L-E-U "B" movem os dedos para cima e baixo com a mão parada (significa azul)

104 SÓ ISSO, O MUNDO TER VÁRIOS E OS ANOS PASSADOS ANTIGOS (exp.f. olhar diminuitivo-exclamativo-anos passados) NÃO-TER-PROBLEMA (exp.f. negativo) PASSADO

105 NÃO-TER-PROBLEMA >NADA<, ENTÃO (exp.f. afirmativa)

\section{Considerações finais}

Os pesquisadores deste trabalho são pessoas de comunidades surdas brasileiras, sendo dois surdos e um ouvinte. A realização da pesquisa foi motivada pela inquietação causada, nestes pesquisadores, pelo acirramento das discussões encontradas em diversos âmbitos sociais virtuais ou presenciais, ou seja, em redes sociais, em salas de aula, bares e outros lugares onde diferentes membros de diversas comunidades surdas se encontram atualmente em discussões acaloradas sobre a adequação da utilização ou não de letras nos sinais das línguas de sinais do Brasil e da França.

Algumas dessas discussões demonstram posicionamentos bastante radicais, propondo até mesmo o banimento total das letras nos sinais como sinal de redenção dos surdos e banimento da opressão dos ouvintes e as suas respectivas línguas hegemônicas, o português e o francês. Por outro lado, algumas pessoas chegam a propor que o contato entre as línguas orais e de sinais não apresentam quaisquer tipos de consequências de natureza cultural ou identitária.

Para este trabalho, os pesquisadores optaram por gerar dados em um questionário simples de apenas duas perguntas:

1) DATILOLOGIA BOM OU RUIM? PORQUE? (Tradução livre: A datilologia é boa ou ruim? Por que?

2) QUEM USAR DATILOLOGIA? SURDO IDOSO, PROFESSORES OUVINTES, SURDOS JOVENS ORALIZADOS, SURDOS JOVENS LS ETC. EXEMPLOS CADA UM. (Tradução livre: Quem usa a datilologia? Dê exemplos de como os surdos, os idosos, os professores ouvintes, os surdos jovens oralizados, os surdos jovens usuários de língua de sinais e outros que usam a datilologia.).

Essas perguntas foram feitas a pessoas que, de alguma forma, foram encontradas envolvidas em alguma discussão sobre o assunto do uso das letras nos sinais, tendo sido escolhidas dentro do critério de serem todas surdas e de nível de escolarização superior, sendo seis jovens alunos brasileiros e um professor adulto francês. 


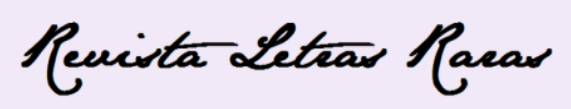

ISSN: 2317-2347 - Vol. 5, Ano 5, № 1 - 2016

Aos pesquisadores, foi uma oportunidade importante para a constatação de que os surdos da atualidade estão preocupados com as suas questões identitárias e culturais sem, no entanto, repetir o padrão notório de sofrimento e opressão causado pelos ouvintes oralistas, discurso este que esteve vigindo durante décadas a fio sem necessariamente estar atrelado a propostas concretas de solução. Hoje a discussão se qualificou e as narrativas analisadas demonstraram posicionamentos claros e concatenados, que consideram as dificuldades pelas quais passam as minorias linguísticas sob o viés dos estudos culturais e com pensamento articulado, acatando que o início do uso das letras nos sinais se perde no tempo e enxergando que, na interação proporcionada pelas línguas em contato, há oportunidades de construção de conhecimento.

A melhoria da educação dos surdos e o avanço do acesso à comunicação proporcionado pelas novas tecnologias têm méritos óbvios sobre o povo surdo e as comunidades surdas. Ainda há equívocos relativamente ingênuos, como propostas de banimento de configurações de mãos referentes às letras no léxico das línguas de sinais, mas em geral o discurso surdo parece ter se qualificado e, no contexto analisado, foi claramente considerado o fenômeno de empréstimo linguístico e a mutação semântica, pragmática e discursiva pelo qual passam a Libras e a LSF devido ao contato com o português e o francês, respectivamente, sem que o perigo do "desaparecimento das línguas de sinais" fosse posto em pauta.

Este trabalho conclui que, a partir da consideração da importância da dinâmica das línguas em contato e do que este fenômeno sócio histórico pode trazer em termos de benefícios ao povo surdo e às comunidades surdas, o uso de letras nos sinais das línguas de sinais pode representar, em alguma medida, o que FAIRCLOUGH ([1994] 2005) chama de "tendência à democratização dos discursos", onde empréstimos lexicais de letras nos sinais podem contribuir para o aprofundamento da construção do conhecimento surdo.

\section{Referências}

BAKHTIN, Mikhail Mijkhailovitch. Estética da criação verbal. Tradução de Maria Ensantina Galvão G. Pereira. São Paulo, SP: Martins Fontes, 1997.

BAUMAN, Zygmunt. Identidade: entrevista a Benedetto Vecchi. Tradução: Carlos Alberto Medeiros. Rio de Janeiro: Zahar, 2005.

BRASIL. Decreto $n^{\circ}$ 5.626, de 22 de dezembro de 2005. Regulamenta a Lei $n^{\circ} 10.436$, de 24 de abril de 2002, que dispõe sobre a Língua Brasileira de Sinais - Libras, e o art. 18 da Lei no 


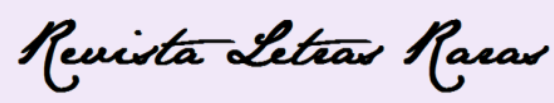

ISSN: 2317-2347 - Vol. 5, Ano 5, № 1 - 2016

10.098, de 19 de dezembro de 2000. Diário Oficial da República Federativa do Brasil, Brasília, DF, 23 dez. 2005. http://www.planalto.gov.br/CCIVIL/_Ato20042006/2005/Decreto/D5626.htm [acesso em 16 nov. 2007].

BRASIL. Lei $n^{\circ}$ 10.436, de 24 de abril de 2002. Dispõe sobre a Língua Brasileira de Sinais Libras e dá outras providências. Diário Oficial da República Federativa do Brasil, Brasília, DF, 25 abr. 2002. Disponível: http://www.planalto.gov.br/CCIVIL_03/Leis/2002/L10436.htm [acesso em 16 nov. 2007].

CASTRO, Nelson Pimenta de. A tradução de fábulas seguindo aspectos imagéticos da linguagem cinematográfica e da língua de sinais. Dissertação de Mestrado em Estudos da Linguagem. Universidade Federal de Santa Catarina, Florianópolis SC: 2012.

Exame.com. Revista online http://exame.abril.com.br/mundo/noticias/oms-afirma-que-60dos-casos-de-surdez-podem-ser-prevenidos [capturado em 09/04/2016].

FABRÍCIO, Branca Falabella e BASTOS, Liliana Cabral. Narrativas e identidade de grupo: a memória como garantia do "nós" perante o "outro". In: PEREIRA, Maria das Graças Dias, Clarissa Rollin Pinheiro Bastos \& Tânia Conceição Pereira (orgs.). Discursos socioculturais em interação. Rio de Janeiro RJ: Editora Garamond Ltda. 2009.

FAIRCLOUTH, N. Conversationalization of public discourse and the authority of the consumer in ABERCROMBIE N., KEAT R. e ROUTLEDGE N. The Authority of the Consumer. London, UK: Routledge, 2005.

FREITAS, Luiz Carlos Barros de. A Hegemonia da Língua Portuguesa e a Legalização da Libras no Brasil. Monografia de Pós-Graduação Lato sensu em Libras: Ensino, Tradução e Interpretação. Rio de Janeiro RJ: UFRJ, 2013.

FREITAS, Luiz Carlos Barros de. A Internet e a educação a distância dos surdos no Brasil: Uma experiência de integração em um meio excludente. Dissertação de mestrado em Design em Situações de Ensino e Aprendizagem, Rio de Janeiro RJ: PUC-Rio, 2009.

GARCEZ, Pedro de Moraes; BULLA, Gabriela da Silva; LODER, Letícia Ludwig. Práticas de pesquisa microetnográfica: geração, segmentação e transcrição de dados audiovisuais como procedimentos analíticos plenos. D.E.L.T.A., v. 30, n. 2, p. 257-288, 2014.

HALL, Stuart. A identidade cultural na pós-modernidade. Tradução de Tomaz Tadeu da Silva e Guacira Lopes Louro. Rio de Janeiro RJ: DP\&A Editora, 2006.

LANE, Harlan L. A Journey into the Deaf-World. San Diego CA USA: DawnSignPress, 1996.

NASCIMENTO, Cristiane Batista do. Empréstimos Linguísticos do Português na Língua de Sinais Brasileira - LSB: Línguas em Contato. Dissertação de Mestrado. Brasília, DF: UnB, 2011 [e-book].

PIMENTA, Nelson. QUADROS, Ronice Muller de. Curso de Libras 1. Rio de Janeiro, RJ: LSB Vídeo, 2013.

QUADROS, Ronice Muller de. KARNOPP, Lodenir Becker. Lingua de sinais Brasileira, Estudos linguísticos. Porto Alegre, RS: Artmed, 2004.

QUADROS, Ronice Muller de (org.). Estudos surdos I. Petrópolis, RJ: Arara Azul, 2006.

RODRIGUES, Isabel Cristina. Baalbaki, Angela Corrêa Ferreira. Práticas sociais entre línguas em contato: os empréstimos linguísticos do português à Libras. Rev. bras. linguist. 


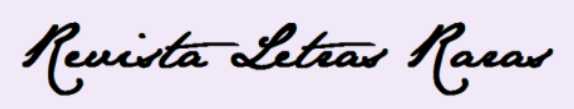

ISSN: 2317-2347 - Vol. 5, Ano 5, № 1 - 2016

apl. vol.14 no.4 Belo Horizonte out./dez. 2014 Epub 29-Ago-2014. http://dx.doi.org/10.1590/S1984-63982014005000021 [capturado em 23/03/2016]

SILVERMAN, David. Qualitative Research 3rd Edition. Cornwall, Great Britain: TJ International Ltd.: 2011.

SKLIAR, Carlos (Org.). A Surdez: Um Olhar Sobre as Diferenças. Porto Alegre RS Brasil: Editora Mediação, [1998] 2005.

STROBEL, Karin. As imagens do outro sobre a cultura surda. Florianópolis, SC: Editora da UFSC, 2008.

THOMA, Adriana da Silva e Maura Corcini Lopes (org.). A invenção da Surdez. entidade e diferença no campo da educação. Santa Cruz do Sul RS: EDUNISC. 2005.

THOMA, Adriana da Silva e Maura Corcini Lopes (org.). A invenção da Surdez II. Espaços e tempos de aprendizagem na educação de surdos. Santa Cruz do Sul RS: EDUNISC. 2006.

Anexo 1: Quadro de Configurações de mãos, CM (Castro, 2012)

\section{Configuraçőes de Mãos}

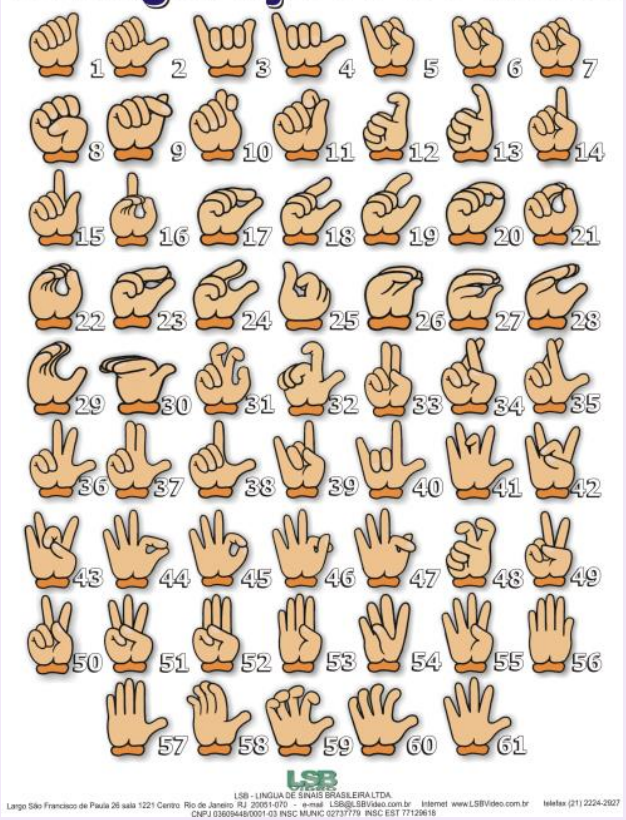

Recebido em: 29/04/2016

Aceito em: 30/06/2016 